\title{
Cancer survival and social class in Sweden
}

\author{
DENNY VÅGERÖ ${ }^{12}$ AND GUNNAR PERSSON ${ }^{2}$ \\ From the Department of Social Medicine, ${ }^{1}$ Karolinska Institute, Huddinge University Hospital, S-141 86 \\ Huddinge, Sweden and Department of Epidemiology, ${ }^{2}$ National Institute of Environmental Medicine, S-104 01 \\ Stockholm, Sweden
}

SUMmARY A study of 98000 cases in the Swedish Cancer Registry from 1961 to 1979 was undertaken. The relative survival by social class was calculated. There was a higher survival probability for white collar workers than for blue collar workers or self-employed farmers for all cancer, as well as for particular cancers, such as, for instance, cancer of the breast and cervix among women and cancer of the rectum among men. For lung cancer, cancer of the stomach, and pancreatic cancer there were no detectable differences in survival probability. The findings can be considered in the the light of various possible explanations, for instance, early detection, differential treatment, and host factors.

In studies from several countries, cancer risks have been shown to be associated with socioeconomic position or social class. ${ }^{1-4}$ These studies have been based on either morbidity or mortality data. Inferring cancer risks from mortality data was advocated by Doll and Peto, in a recent publication, as being preferable to morbidity data for reasons of data quality and accuracy. ${ }^{5}$ However, inferring the social class distribution of cancer risks from mortality data may give a biased result if cancer survival is linked also to socioeconomic position. For instance, in a social group with a relatively high probability of survival after diagnosis the event of death will tend to be postponed. Consequently, their mortality will appear relatively low even if incidence of the disease is identical with that of a comparison group.

In several studies survival has been shown to be associated with social class, socioeconomic position or economic status. ${ }^{6-9}$ Hence there is in principle a possibility that studies inferring health risks from mortality data are confounded by differential survival.

Since survival is measured as the time period from date of diagnosis to date of death, an earlier date of diagnosis will be reported as a longer survival, even without any improvement of prognosis whatsoever. If the social class differences in survival could be reduced to such a bias of early detection/diagnosis, they would be trivial indeed. Early detection may also result in diagnosing a group of more benign tumours, and thus the average survival for early cancers may for that reason be better. Those papers that have reported that differences in survival probability exist have not, however, concluded that these differences are trivial nor that they could be reduced to variation in the proportion of less malignant tumour types.

The theory that the prognosis of the cancer after it clinical recognition is associated with social position ist consistent with at least two possible explanations? Firstly, differential treatment could influence survivas probabilities. Such differences in treatment could $\mathbb{D}$ particularly for some cancers (such as breast cancer) be due to early diagnosis. Early diagnosis would the represent a truly better prognosis. Differentiat: treatment could also be the result of the quality of care and access to resources. This would be possible for those cancers where treatment is scarce and at the same time represents a genuine improvement of prognosis, which it does not do for all cancer sites.

Secondly, and of great theoretical interest, is the possibility that survival after diagnosis may be influenced by host factors, in particular those which reflect the person's social and psychological context. This assumption has been discussed frequently in the literature, ${ }^{10-13}$ but there is only circumstantial evidence for such a theory. The theoretical argument has usually been along the lines that social support and psychological wellbeing may enhance the immune system's chances of confining the development of a tumour. It should perhaps be pointed out here that host susceptibility associated with low socioeconomic position could be accounted for in other ways as well, for instance nutritional history.

In an earlier paper we reported Swedish data on the social class distribution of various cancer sites. ${ }^{3}$ In this paper we try to answer the question whether there is indeed also a difference in relative cancer survival by social class in Sweden. The further question about the basis for such differences will be discussed briefly, but 
the present material does not not permit a more significant contribution to that issue.

\section{Population under study}

The population under study is derived from the Swedish Cancer Environment Registry. This registry has previously been described by several authors. ${ }^{14}$ is Although its main application has been in studying the occurrence of cancer by occupation or other groups, its potential for survival analysis has also been demonstrated. ${ }^{916}$ The registry was created through linking the Swedish Cancer Registry 1961-79 to the 1960 population census. From the census information classes of a similar socioeconomic position could be formed.

All cancer cases of those persons who were in the economically active population at the census date were classified by socioeconomic position. The classification is based on one of the variables in the census, defined as "occupational status" (yrkesställning) and previously used to define social class. This classification is described in more detail elsewhere. ${ }^{3}$

For the purpose of survival analysis the following five groups are included: male and female blue collar workers, male and female white collar workers, and self-employed men in agriculture. Other groups were excluded because there were too few cases. In this study only cases diagnosed at age 20 to 64 are included. Thus, the study is based on a total of 98372 cancer cases. The distribution of cases by site and social class is demonstrated in the table.

\section{Methods}

Survival probabilities for a particular cancer and a specific social class have been calculated in the following way:

Cases diagnosed in 1961 and onwards were followed up until the date of death or 31 December 1979. The observed number of deaths among these cancer cases was compared with the expected number, assuming the same survival chances as in the general male or female population, these being calculated from life tables. ${ }^{1518}$ The ratio of observed to expected deaths gives the relative survival of cancer cases. This is done for first-year, second-year, third-year, fourth-year, and fifth-year survival. The cumulative relative survival probability is obtained by multiplying the probability of surviving the first, second, third, fourth, and fifth year. When the number of cases at risk at the beginning of the year is less than ten, no calculations are made. This method is described in more detail in references ${ }^{19}$ and ${ }^{20}$ Cases diagnosed post mortem were excluded from the survival analysis.

No information was available for this study on stage of tumour development at the date of diagnosis. However, all cases included were classified as malignant by the registry.

The relative survival was calculated for all cancer and for 13 selected localisations. Figure 3 represents relative survival probabilities for those cancer sites. For reasons of space, only the male survival curves are demonstrated for some sites, although the text comments on both male and female survival.

Those sites presented were selected because they are common or because they have previously demonstrated a strong association of survival with social class or been discussed in the literature in this context.

\section{Results}

Figures 1 and 2 demonstrate that there are differences

Table 1 Number of cancer cases followed up for survival 1961-79 and included in the study, by site (only those sites studied) and socioeconomic group

\begin{tabular}{|c|c|c|c|c|c|c|c|}
\hline \multirow[b]{2}{*}{ Site } & \multicolumn{2}{|c|}{$\begin{array}{l}\text { White collar } \\
\text { workers }\end{array}$} & \multicolumn{2}{|c|}{$\begin{array}{l}\text { Blue collar } \\
\text { workers }\end{array}$} & \multirow{2}{*}{$\begin{array}{l}\begin{array}{l}\text { Self- } \\
\text { employed }\end{array} \\
\text { Men }\end{array}$} & \multicolumn{2}{|c|}{$\begin{array}{l}\text { All studied } \\
\text { groups }\end{array}$} \\
\hline & Men & Women & Men & Women & & Men & Women \\
\hline Stomach & 1040 & 573 & 3383 & 629 & 606 & 5029 & 1202 \\
\hline Colon & 1381 & 1036 & 2447 & 910 & 310 & 4138 & 1946 \\
\hline Rectum & 801 & 547 & 1858 & 501 & 316 & 2975 & 1048 \\
\hline Pancreas & 669 & 325 & 1419 & 320 & 184 & 2272 & 645 \\
\hline Lung & 1890 & 470 & 4697 & 483 & 277 & 6864 & 953 \\
\hline Breast & - & 7230 & - & 4301 & & $-\quad$ & 11531 \\
\hline Cervix & - & 1992 & - & 2095 & & - & 4087 \\
\hline Corpus uteri & - & 1689 & - & 1210 & . & - & 2899 \\
\hline Ovaries & - & 1911 & - & 1539 & & - & 3450 \\
\hline Prostate & 1592 & - & 3160 & - & 575 & 5327 & - \\
\hline Testis & 387 & - & 583 & - & 45 & 1015 & - \\
\hline Kidney & 1108 & 443 & 1980 & 427 & 273 & 3361 & 870 \\
\hline Bladder & 1317 & 360 & 2485 & 278 & 234 & 4036 & 638 \\
\hline Other & 7476 & 5461 & 14751 & 4282 & 2116 & 24343 & 9743 \\
\hline All sites & 17661 & 22037 & 36763 & 16975 & 4936 & 59360 & 39012 \\
\hline
\end{tabular}




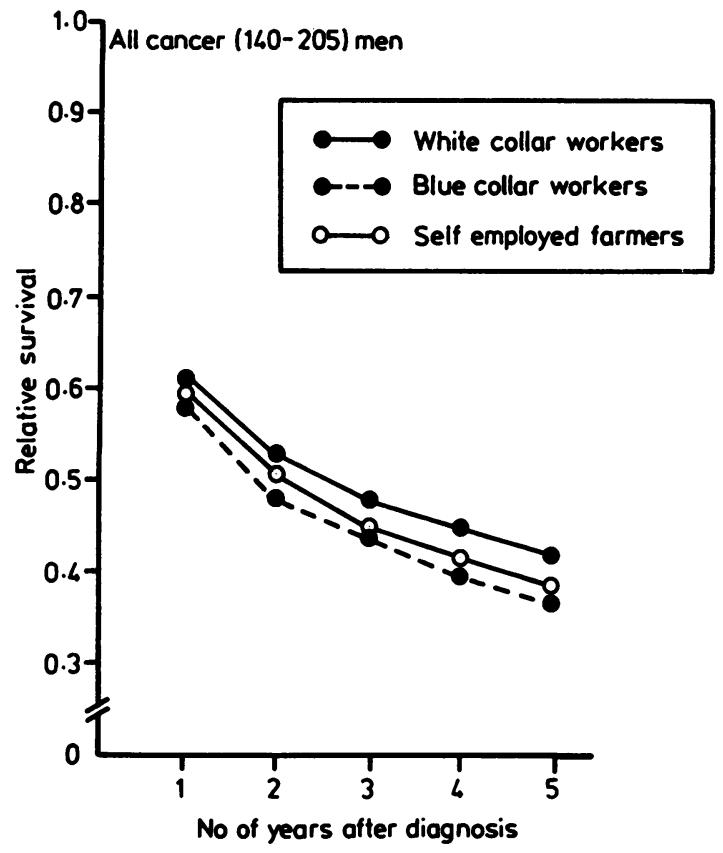

Fig 1 All cancer (140-205) in men.

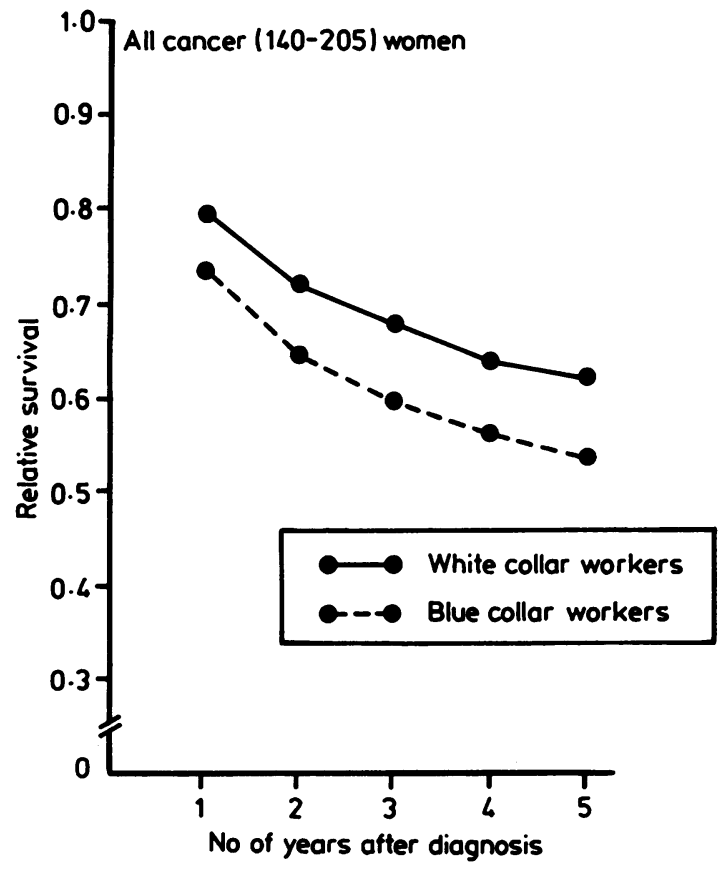

Fig 2 All cancer (140-205) in women. in relative survival for all cancer, that is, if we regard cancer as an entity and disregard the information on the site of the cancer. As will be clear from the text below, this is partly, but not totally, due to the site distribution of cancer in the compared groups.

Figure 3 shows site specific analyses. For lung cancer there is virtually no difference between the three groups of men. The same is true also when white and blue collar women are compared.

For stomach cancer there is hardly any difference between the compared groups among either men or women.

Cancer of the pancreas demonstrates a very low survival in all groups and no appreciable differences.

For all these sites the five year relative survival was very low, that is, well below 0.2 in all groups.

For cancer of the colon and cancer of the rectum the survival chances were better for white collar workers, especially in comparison with self-employed farmers (men). Again, white collar workers have a better survival with regard to cancer of the kidney, when compared with blue collar workers, both men and women. The survival advantage when compared with farmers is smaller.

For these three sites the five year relative survival is clearly better than for the preceding groups of cancers, that is, between 0.34 and 0.52 in those groups studied.

Looking at female reproductive cancers, we notice a clear difference in relative survival for cancer of the ovaries, cancer of the cervix, cancer of the corpus uteri, and cancer of the breast. The pattern is always the same-a better survival for the white collar working women compared with blue collar working women. This is so irrespective of whether the cancer itself is more common among white collar working women (as, for instance, is cancer of the breast) or less common in the group (as, for instance, is cancer of the cervix).

Five year relative survival here ranges from 0.40 to 0.89 in the studied groups.

Finally, for a group of cancers where the five year relative survival always exceeds 0.50 we find again some differences between those groups compared. There may be a slight advantage for white collar workers with regard to cancer of the prostate. For cancer of the testis, white collar workers do better in particular when compared with self-employed farmers.

There is also a tendency for white collar workers to be at an advantage with regard to bladder cancer in men (especially compared with blue collar workers) as well as in women.

In general, the differences observed are remarkably consistent. With the exception of those cancers where survival is extremely low, there seems to be a 

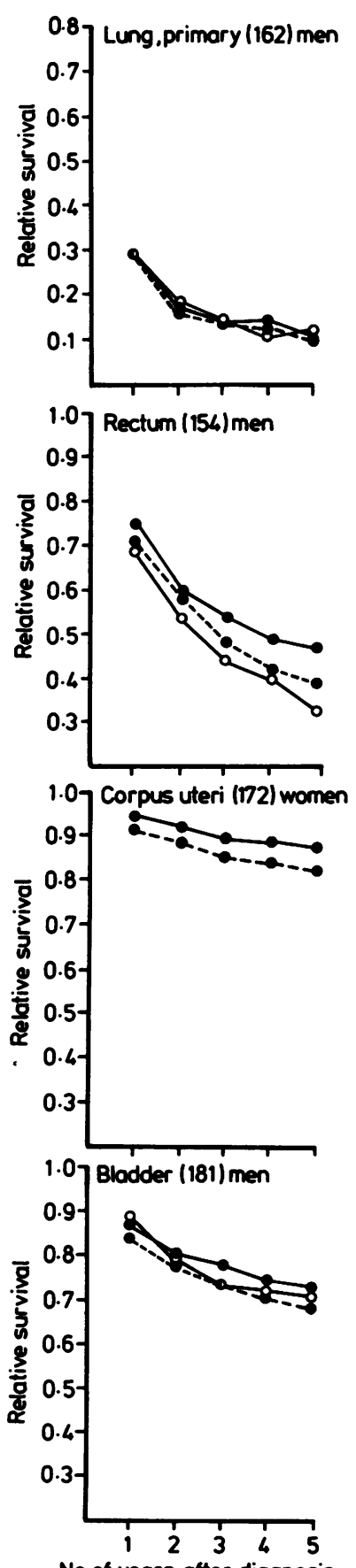

No of years after diognosis
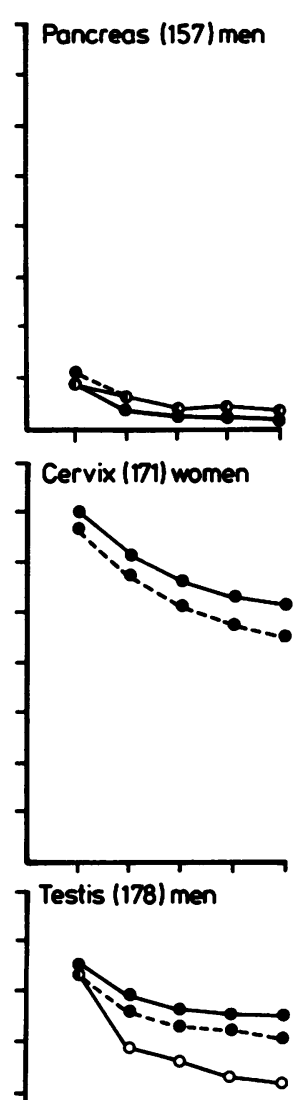

$\longrightarrow$ White collar workers

$\rightarrow$ Blue colliar workers

๑ 0 Self employed farmers
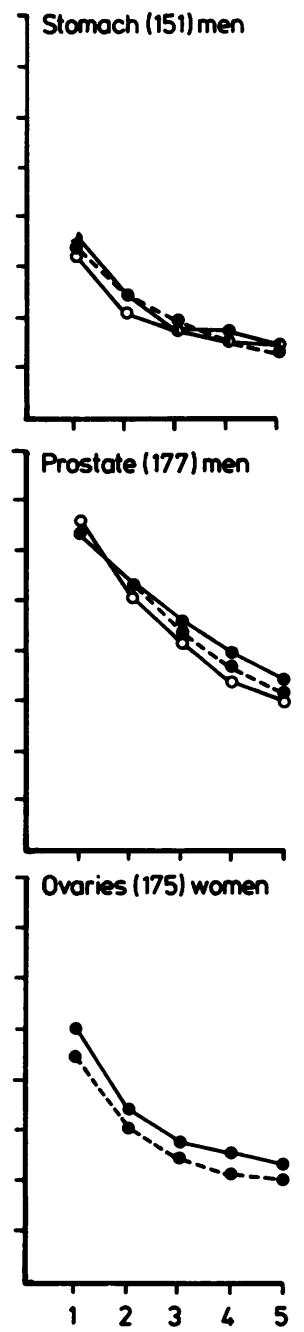

No of years ofter diagnosis
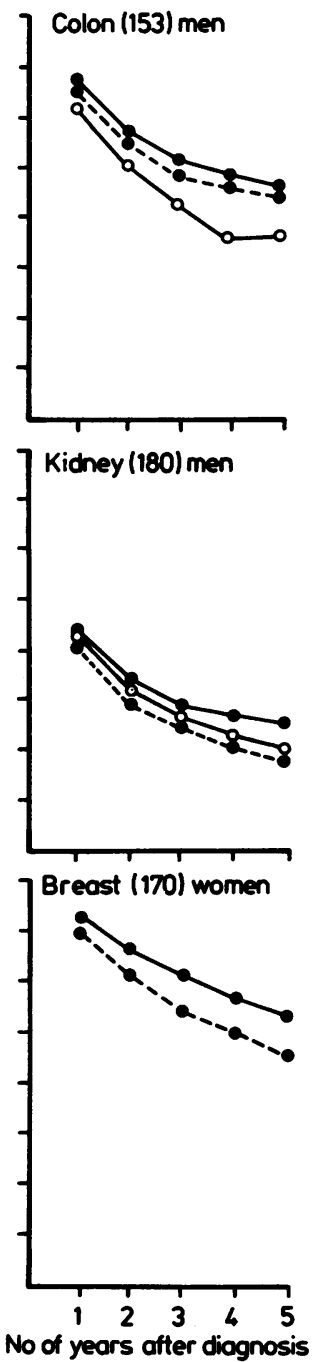

No of years after diagnosis

Fig 3 Relative survival. 
systematic and site independent difference in survival chances, with some advantage for white collar workers, both men and women.

\section{Discussion}

Interpreting the observed seemingly systematic differences in cancer survival by social class, we would have to consider the following possible explanations:

1 Early detection of cancer (without improvement of prognosis) is more common in white collar workers.

2 Early detection (with some improvement of prognosis) is more common in white collar workers.

3 Differential treatment resulting in differential prognosis favours white collar workers.

4 Differences attributable to host factors influence body susceptibility or body response to cancer.

5 There are differences attributable to the biological properties of the tumours compared, for instance, with distribution of histological types for a particular cancer localisation.

The first explanation and the second, in part, would lead to differences that were statistical artefacts owing to the way in which survival time is measured. The second (partly), the third, and the fourth explanations would imply that survival chances were different, even if the biological stage of the cancer was the same at the time of diagnosis. These possibilities are considered in examples below. Those cancers that demonstrated no survival differences are also considered.

Lung cancer, for instance, demonstrated no appreciable difference between the groups compared. This is in line with earlier findings reported in the literature, for instance, Keirn. ${ }^{21}$ Hakulinen, comparing national survival rates for Norway and Finland, found no differences in lung cancer survival in spite of such differences appearing for many other cancers. ${ }^{22}$ Lung cancer, being a relatively lethal cancer and with relatively low chances of early detection, seems likely to be less affected by whatever factors contribute to differential cancer survival.

If lung cancer survival is influenced by host factors or factors of the immediate social and psychological environment, it is clear that the classification into social classes taken at one particular point in time is too crude to demonstrate such an influence. We could not exclude the possibility that a more thorough knowledge of individual life histories could reveal that some survival difference existed even for lung cancer.

Female breast cancer, as another example, demonstrates a striking contrast in survival probability when blue and white collar women are compared. An earlier study by Zollinger, ${ }^{23}$ comparing survival rates of Seventh-Day Adventists with others, concluded that such risk factors for breast cancer as parity and age at first pregnancy did not contribute to differential survival. The group of white collar women in our study has previously been shown to be at higher risk for breast cancer, possibly due to low parity and late first pregnancy. Since they in fact have a better survival, this could not be explained by the same set of factors that contributes to their higher risk. It is more likely that early diagnosis and subsequent early treatment contribute to a better prognosis.

It is clear that the difference in breast cancer survival cannot merely be a statistical artefact of early diagnosis. We compared survival probabilities on the assumption that all cases of breast cancer among white collar women would be diagnosed one year later than they actually were, but this did not change the pattern of better survival for white collar women compared with blue collar women.

In general, in this study it is not possible to separate the beneficial effect of early diagnosis/better treatment from any independent host factor mediated effect of socioeconomic position on survival probability given a certain stage of tumour development. Other studies have suggested either that socioeconomic status has no effect at all, ${ }^{21}$ or that it contributes to survival more than that of early or better treatment. ${ }^{23} 24$

Chirikos, trying to assess the simultaneous effects of various factors on survival, made the interesting observation that the effect of socioeconomic status on $\delta$ survival was of particular importance in an earlier stage of tumour development. ${ }^{25}$ If this is the case, discovering a host factor mediated effect of socioeconomic status may be conditional on the possibility of early diagnosis of that cancer. This seems to be a hypothesis that should be further explored.

In an analysis of feelings of wellbeing among cancer survivors compared with healthy controls, Schmale et al found small differences. The one particular exception was that feelings of lack of control over one's own life were more common among cancer survivors compared with healthy controls. ${ }^{26}$ They also found that such feelings were modified by educational level and marital status. Feelings of wellbeing, especially control over one's own life situation, among cancer patients are clearly but not exclusively influenced by the severity of the disease. Such feelings might also be modified by the social environment of those patients. In a recent study of breast cancer, Pettingale et al found evidence that patients' mental attitudes to cancer were an additional prognostic factor. ${ }^{27}$ Whether such factors also contribute to the survival differences observed in this study is a justified speculation.

Finally, the distribution of histological types of a particular cancer localisation may vary between the socioeconomic groups compared. This may produce 
survival differences. However, it seems unlikely that such a possibility could give rise to those systematic differences that we have observed.

This study was supported by the Committee for Social Research of the Swedish Health Ministry (grant DSF F85/2025) and by the Swedish Council for Planning and Coordination of Research (grant FRN A1-5/ 2004).

\section{References}

${ }^{1}$ Logan WPD. Cancer mortality by occupation and social class 1851-1971. IARC Scientific Publication No. 36. London and Lyon, 1982.

2 Leon D. The social distribution of cancer: OPCS Longitudinal Study 1971-75. OPCS series LS3, London: HMSO (in press).

${ }^{3}$ Vågerö $D$, Persson $G$. Occurence of cancer in socioeconomic groups in Sweden. An analysis based on the Swedish Cancer Environment Registry. Scand J Soc Med 1986; 14: 151-60.

${ }^{4}$ Rimpelä A, Pukkula E. Syöpätaudit ja socioekonomiset tekijät. (Survival and socioeconomic class.) Sociaalilääketieteel linen Avikakauslehti 1984; 21: 61-75.

${ }^{5}$ Doll R, Peto R. The causes of cancer. Quantitative estimates of avoidable risks of cancer in the United States today. Oxford University Press, 1981.

${ }^{6}$ Leon D, Wilkinson R. Inequalities in prognosis. Social class differences in cancer and heart disease survival. Paper presented at the European Science Foundation Workshop on Inequalities in Health, London, September 1985.

${ }^{7}$ Lipworth L, Abelin T, Connely R. Socioeconomic factors in the prognosis of cancer patients. J Chron Dis 1970; 23: 105-116.

${ }^{8}$ Berg J, Ross R, Latourette H. Economic status and survival of cancer patients. Cancer 1977; 39: 467-77.

${ }^{9}$ Vågerö D, Persson G. Risks, survival and trends of malignant melanoma among white and blue collar workers in Sweden. Soc Sci Med 1984; 19(4): 475-8.

${ }^{10}$ Fox B. Premorbid psychological factors as related to cancer incidence. Behaviour Med 1978; 1 (1): 45-133.
11 Schmale A, Inker H. Hopelessness as a predictor of cervical cancer. Soc Sci Med 1971; 5: 95-100.

12 Cox T, Mackay C. Psychosocial factors and psychophysiological mechanisms in the aetiology and development of cancers. Soc Sci Med 1982; 16: 381-96.

13 Riley V. Psychoneuroendocrine influences on immunocompetence and neoplasia. Science 1981; 212: $1100-9$.

14 Vågerö D, Olin R. Cancer incidence in the electronics industry in Sweden, using the Swedish Cancer Environment as a screening instrument. $\mathrm{Br} J$ Industr Med 1983; 40: 188-92.

15 Wiklund K, Einhorn J, Wennström G, Rapaport E. A Swedish Cancer Environment Register available for research. Scand J Work Environ Health 1981; 7: 64-7.

16 Persson G, Ahlbom A, Norell S, Ruthquist L, Vảgerö D. Har överlevnaden för cancersjuka ökat från 1960-tal till1970-tal? (Has cancer survival improved from the $60 \mathrm{~s}$ to the 70s?) Läkartidningen 1985; 82: 3305-10.

17 Sveriges Officiella Statistik. SCB. Folkmängdens förändringar 1964. Stockholm; Liber Förlag 1965.

18 Sveriges Officiella Statistik. SCB. Folkmängdens förändringar 1979. Stockholm; Liber Förlag 1980.

19 Office of Population Censuses and Surveys. Cancer Statistics: Survival. 1971-75 registrations. Series MBI, no 9. London; HMSO, 1982

20 The Cancer Registry of Norway. Survival of cancer patients. Cases diagnosed in Norway 1968-75. Oslo, 1980.

${ }^{21}$ Keirn W, Metter G. Survival of cancer patients by economic status in a free care setting. Cancer 1985; 55: 1552-5.

22 Hakulinen T. A comparison of nationwide cancer survival statistics in Finland and Norway. World Health Stat Quart 1983; 36: 35-46.

${ }^{23}$ Zollinger TW, Phillips RL, Kuqma JW. Breast cancer survival rates among Seventh-Day Adventists and nonSeventh-Day Adventists. Am J Epidemiol 1984; 119: 503-9.

${ }^{24}$ Dayel HH, Power RN, Chiu C. Race and socioeconomic status in survival from breast cancer. J Chron Dis 1982; 35: $675-83$.

${ }^{25}$ Chirikos TN, Reiches NA, Moeschberger ML. Economic differentials in cancer survival: A multivariate analysis. $J$ Chron Dis 1984; 37: 183-93.

${ }^{26}$ Schmale AH, Morrow GR, et al. Wellbeing of cancer survivors. Psychosom Med 1983; 45(2): 163-9.

${ }^{27}$ Pettingale KW, Morris T, Greer S, Haybittle JL. Mental attitudes to cancer: An additional prognostic factor. Lancet 1986: i: 750 . 